\title{
Cochrane aktivnosti u Hrvatskoj
}

\section{Cochrane activities in Croatia}

\author{
Livia Puljak*, Irena Zakarija-Grković, Tina Poklepović Peričić
}

Hrvatski Cochrane, Medicinski fakultet u Splitu, Split

\author{
*Dopisni autor: \\ izv. prof. dr. sc. Livia Puljak, dr. med. \\ Hrvatski Cochrane, \\ Medicinski fakultet u Splitu \\ Šoltanska 2, 21000 Split \\ e-mail: livia.puljak@mefst.hr
}

\begin{abstract}
Sažetak. Ogranak Cochrane kolaboracije osnovan je u Hrvatskoj pri Medicinskom fakultetu u Splitu 2008. godine s ciljem promoviranja medicine temeljene na dokazima i sustavnih pregleda u Hrvatskoj i regiji. Hrvatski Cochrane 2017. godine postao je punopravni samostalni Cochrane centar kao prvi i jedini takav centar u jugoistočnoj Europi. Hrvatski Cochrane ima brojne aktivnosti. Svake godine organizira Hrvatski Cochrane simpozij u Splitu i provodi brojne aktivnosti edukacije zdravstvenih radnika i laika. Kroz programe popularizacije znanosti organizirane su aktivnosti za udruge pacijenata, novinare i studente novinarstva te za širu javnost. Od 2013. godine prevode se laički sažetci Cochrane sustavnih pregleda na hrvatski jezik i do danas ih je prevedeno 2.500. Hrvatski Cochrane potiče uvođenje principa medicine temeljene na dokazima u formalno obrazovanje zdravstvenih radnika. Hrvatska Cochrane partnerska mreža uključuje profesionalna društva, državne institucije i udruge pacijenata iz Hrvatske i regije; ti partneri formalno su se pridružili Hrvatskom Cochraneu u promicanju zdravstvene skrbi temeljene na dokazima. Broj Cochrane autora i Cochrane publikacija iz Hrvatske kontinuirano se povećava, što pokazuje da se hrvatski istraživači počinju uključivati u svjetske trendove istraživanja u području medicine temeljene na dokazima. Sustavni pregledi mogu se usvojiti i kao model doktorata. U prvih deset godina od osnutka Hrvatski Cochrane u regiji je postigao zapažene rezultate u promoviranju medicine temeljene na dokazima, što nije jednostavno s obzirom na to da su svi koji su angažirani oko Hrvatskog Cochranea i Cochrane aktivnosti u Hrvatskoj - volonteri. Nadamo da će se isti tempo i entuzijazam zadržati i u budućnosti.
\end{abstract}

Ključne riječi: Cochrane; Hrvatska; medicina temeljena na dokazima; sustavni pregledi

Abstract. A branch of the Cochrane Collaboration was founded in Croatia at the University of Split School of Medicine in 2008 with the aim of promoting evidence-based medicine (EBM) and systematic reviews in Croatia and the region. In 2017, Cochrane Croatia became an independent Cochrane Center, the only such center in the South-East of Europe. Cochrane Croatia conducts numerous activities. A Croatian Cochrane Symposium is organized each year in Split, Croatia. Science popularization projects, funded by the Ministry of Science, Education and Sport, have enabled Cochrane Croatia to organise numerous educational activities for, patient groups, journalists, journalism students, health professionals and the lay public. Since 2013 Cochrane Croatia has been translating Plain Language Summaries (PLSs) of Cochrane Systematic Reviews; in May 2017 there were 2500 translated PLSs. Cochrane Croatia is actively encouraging the introduction of EBM principles into the curriculum for the formal education of healthcare professionals. Cochrane Croatia has a network of partners, including professional associations, government institutions and patient organizations from Croatia and the region. Those partners have formally joined Cochrane Croatia in promoting EBM. The number of Cochrane authors and Cochrane publications from Croatia is continuously increasing. It indicates that Croatian authors are joining international trends in EBM research. Systematic reviews can also be adopted as a model for a PhD thesis. In the first ten years since its foundation Cochrane Croatia has achieved significant results in the whole region via promotion of EBM, which is not a simple achievement, given that all individuals affiliated with Cochrane activities in Croatia are volunteers. We hope that the same enthusiasm and progress will last in future.

Key words: Cochrane; Croatia; evidence-based medicine; systematic reviews 
COCHRANE KOLABORACIJA I OSNIVANJE OGRANKA U HRVATSKOJ

Cochrane kolaboracija osnovana je 1993. u Ujedinjenom Kraljevstvu s ciljem izrade visokokvalitetnih sustavnih pregleda i promoviranja medicine temeljene na dokazima ${ }^{1}$. Cochrane sustavni pregledi u međuvremenu su se nametnuli kao zlatni standard među sustavnim pregledima u medici$n^{2}$. Metodološka i kvaliteta izvještavanja Cochrane sustavnih pregleda ocijenjena je boljom od drugih sustavnih pregleda ${ }^{3-6}$.

Takav standard kvalitete održava se zbog toga što je Cochrane posvećen kontinuiranom ulaganju u poboljšanje metodologije sustavih pregleda, a taj trend širi se dalje na ne-Cochrane sustavne preglede u kojima se preuzimaju metodološki standardi koje Cochrane sustavni pregledi postavljaju . U Hrvatskoj je 2008. osnovan ogranak Cochrane kolaboracije s ciljem promoviranja izrade sustavnih pregleda i medicine temeljene na dokazima u cijeloj našoj regiji.

\section{IME I STATUS ORGANIZACIJE}

Cochrane kolaboracija utemeljena je kao neprofitna udruga, a nazvana je po britanskom liječniku Archieju Cochraneu koji je uvelike pridonio razvoju znanosti, naglašavajući važnost sažimanja dokaza za donošenje odluka u zdravstvu. Od 2016. godine organizacija se zove samo Cochrane. U skladu s tim promijenjena su i imena Cochrane entiteta, pa se umjesto naziva centar i ogranak od tada samo koristi riječ Cochrane i ime države u kojoj se entitet nalazi. U skladu s tim Hrvatski ogranak Talijanskog Cochrane centra službeno je 2016. dobio naziv Hrvatski Cochrane (engl. Cochrane Croatia).

Hrvatski Cochrane djeluje kao organizacijska jedinica Medicinskog fakulteta u Splitu. Zahvaljujući brojnim istaknutim aktivnostima u posljednjih deset godina, kao i velikom entuzijazmu njezinih članova, 2017. godine je Cochrane promovirao Hrvatski Cochrane u status punopravnog samostalnog centra, što je veliko priznanje radu Hrvatskog Cochranea i velika čast, jer je to jedini Cochrane centar u jugoistočnoj Europi.

\section{COCHRANE AKTIVNOSTI U HRVATSKOJ}

I prije osnivanja Cochrane ogranka u Splitu, u Hrvatskoj su se provodile sporadične Cochrane aktiv- nosti, uglavnom kroz rad autora koji su bili uključeni u izradu i uređivanje Cochrane sustavnih pregleda. Tu prednjači istraživačka skupina koju vodi prof. dr. sc. Davor Štimac iz KBC-a Rijeka i Medicinskog fakulteta u Rijeci te njegovi suradnici dr. sc. Vanja Giljača, doc. dr. sc. Goran Poropat i doc. dr. sc. Goran Hauser, koji djeluju kao urednici u Cochrane Hepatobiliary Group te su objavili niz Cochrane sustavnih pregleda iz područja gastroenterologije. Nakon osnivanja Hrvatskog Cochranea 2008. godine počelo je promoviranje Cochrane sustavnih

Hrvatski Cochrane osnovan je 2008. godine. Hrvatski Cochrane postao je samostalan i punopravan Cochrane centar 2017. godine.

pregleda, sustavnih pregleda općenito i medicine temeljene na dokazima u Hrvatskoj i u regiji.

\section{COCHRANE EDUKACIJA}

Svake godine, od 2009., na Medicinskom fakultetu u Splitu organizira se Hrvatski Cochrane simpozij, kao jednodnevni ili dvodnevni međunarodni skup u okviru kojeg predaju domaći i strani stručnjaci iz područja medicine temeljene na dokazima i predstavljaju aktualne teme iz tog područja. Hrvatski Cochrane godinama je održavao dva besplatna internetska tečaja o izradi Cochrane sustavnih pregleda za čije su uspješno završavanje sudionici dobivali bodove Hrvatske liječničke komore. Od 2017. godine ti su tečajevi obustavljeni jer je procijenjeno da nisu dovoljno u skladu $\mathrm{s}$ najnovijom Cochrane metodologijom i trenutno se radi na njihovom obnavljanju.

Volonteri Hrvatskog Cochranea održavaju i cijeli niz ad hoc edukacija za zdravstvene radnike i laike na poziv, u skladu s potrebama publike. Takve edukacije prilagođavaju se potrebama i željama onih koji žele edukaciju, traju od 15 min do $8 \mathrm{~h}$, a sadrže više ili manje opsežne informacije o tome što je Cochrane, što su sustavni pregledi, zašto i kako se izrađuju i na koji način korisnici te informacije mogu koristiti u svom svakodnevnom radu i životu.

Skraćeni prikazi Cochrane sustavnih pregleda objavljuju se svaki mjesec u Liječničkim novinama, službenom glasilu Hrvatske liječničke komo- 
re, kao i u drugim časopisima namijenjenim zdravstvenim radnicima na poziv urednika. Takvu rubriku redovito objavljuje Medix, a tekstove o Cochraneu objavljuju i glasila komora drugih zdravstvenih radnika, uključujući Sestrinski glasnik, Primaljski vjesnik, Vjesnik dentalne medicine i Bilten Hrvatske ljekarničke komore.

Na poticaj Hrvatskog Cochranea u visokoškolsku edukaciju zdravstvenih radnika u Hrvatskoj uvode se nastavne cjeline i predmeti u kojima se promovira medicina temeljena na dokazima. Tako u

Formalna i neformalna edukacija zdravstvenih radnika o principima medicine temeljene na dokazima glavni je cilj Hrvatskog Cochranea.

sklopu vertikaliziranog i sveobuhvatnog nastavnog programa Katedre za istraživanja u biomedicini i zdravstvu Medicinskoga fakulteta Sveučilišta u Splitu studenti imaju priliku naučiti mnogo o principima medicine temeljene na dokazima, njenim metodološkim i kliničkim značajkama, od postavljanja kliničkog pitanja, pretraživanja literature, kritičke procjene dokaza, evaluacije rezultata i njihove opravdanosti i primjenjivosti $u$ zadanim kliničkim situacijama, a napose o radu Cochranea i Cochrane sustavnim preglednim radovima. Otprilike 500 studenata godišnje na Sveučilište u Splitu, sa studija medicine, dentalne medicine, farmacije, zdravstvenih studija i forenzike i na poslijediplomskim doktorskim studijima Medicinskog fakulteta u Splitu, slušaju o principima, primjeni i provedbi medicine temeljena na dokazima. Također se na Hrvatskom katoličkom sveučilištu od 2016. godine nudi izborni predmet na studiju sestrinstva pod nazivom Cochrane metodologija i sustavni pregledi.

\section{HRVATSKA COCHRANE PARTNERSKA MREŽA}

Na Hrvatskom Cochrane simpoziju održanom 2013. godine predstavljena je ideja stvaranja partnerske mreže Hrvatskog Cochranea. Pozvani su svi korisnici Cochrane dokaza na organizacijskoj razini, uključujući profesionalna društva, državne institucije i udruge pacijenata iz Hrvatske i regije, da se formalno pridruže Hrvatskom Cochraneu u promicanju zdravstvene skrbi temeljene na dokazima. Trenutno Hrvatski Cochrane ima 17 služ- benih partnera, od kojih su osam stručna društva i institucije, uključujući jedno iz $\mathrm{BiH}$, te devet udruga pacijenata.

Partneri Hrvatskog Cochranea aktivno sudjeluju u svim aktivnostima Hrvatskog Cochranea, od sudjelovanja na simpozijima i Cochrane kolokvijima, do organizacije radionica i prevođenja Cochrane dokaza. O svim partnerskim aktivnostima redovito se izvještava na mrežnim stranicama Hrvatskog Cochranea, kao i u elektroničkom listu Cochrane novine koji izlazi triput godišnje.

POPULARIZACIJA ZNANOSTI I PRIJENOS ZNANJA LAICIMA

Hrvatski Cochrane u početku je bio orijentiran isključivo na zdravstvene radnike, ali su s vremenom provedene brojne aktivnosti namijenjene laicima kroz niz projekata popularizacije znanosti. Prvi takav projekt od Ministarstva znanosti, obrazovanja i sporta dobila je 2012. doc. dr. sc. Irena Zakarija Grković, suvoditeljica Hrvatskog Cochranea. U okviru tog projekta počelo je prevođenje laičkih sažetaka Cochrane sustavnih pregleda (engl. plain language summary) na hrvatski jezik. Taj projekt nastavljen je volonterskim naporima i nakon što je završen, tako da u vrijeme pisanja ovoga rada (svibanj 2017.) imamo prevedeno gotovo 2.500 sažetaka Cochrane sustavnih pregleda, od čega ih je 2.300 objavljeno na stranici Cochrane dokazi

Za potrebe objave i popularizacije laičkih sažetaka Cochrane sustavnih pregleda 2013. godine napravljena je Facebook stranica Cochrane zdravlje koja je u svibnju 2017. imala 3.206 pratitelja. Na Facebook stranici objavljuju se svakodnevno novi prevedeni sažetci Cochrane sustavnih pregleda, kao i druge relevantne vijesti o Cohraneu, Hrvatskom Cochraneu i medicini temeljenoj na dokazima. Promoviranje Cochrane laičkih sažetaka putem društvene mreže Facebook pokazalo se kao izvrstan način prijenosa znanja ${ }^{9}$.

U okviru drugog projekta popularizacije znanosti organizirane su radionice u četiri najveća grada Hrvatske o medicini temeljenoj na dokazima za udruge pacijenata, koje su s Hrvatskim Cochraneom potpisale ugovor o suradnji. U okviru daljnjih projekata popularizacije znanosti organiziran je niz edukacija za članove udruga pacijenata, kao i tiskanje/distribucija edukativnih materijala, po- 
put letaka prevedenih laičkih sažetaka najpopularnijih Cochrane sustavnih pregleda, koji su se dijelili po ordinacijama obiteljske medicine. Projektima popularizacije znanosti iz 2016. godine počelo je snimanje i objavljivanje audiozapisa Cochrane sustavnih pregleda na hrvatskom jeziku. Audiozapisi objavljuju se na mrežnoj stranici Cochrane dokazi, kao i na naslovnoj stranici Hrvatskog Cochranea i na iTunes.

U Hrvatskom Cochraneu prevedena je i na hrvatski jezik objavljena knjiga Gdje su dokazi? Bolja istraživanja za bolje zdravlje. Knjiga je originalno objavljena na engleskom jeziku, u originalu se zove Testing treatments, i napisala su je četiri autora, od kojih su troje liječnici i jedna novinarka. U knjizi se na jednostavan način govori kako možemo znati je li neka terapija sigurna i učinkovita. Pisana je za pacijente, i objašnjava da se svaki postupak u medicini može provjeriti na objektivan način, bez obzira na to radi li se o tableti, kirurškom zahvatu, savjetu, vrsti prehrane itd. Također poziva pacijente da budu skeptični prema terapijama koje obećavaju čuda. To je osobito važno za tzv. alternativne terapije koje obično nisu uopće istražene. Knjiga je objavljena u tiskanom obliku, ali je i besplatno dostupna na internetu u html i pdf obliku ${ }^{10}$.

Prevedene su dvije knjižice s engleskog na hrvatski jezik koje je izdala britanska udruga Razumno o znanosti (engl. Sense About Science); Nemam što izgubiti ako pokušam ${ }^{11}$ i Glas razuma o ranom otkrivanju bolesti ${ }^{12}$.

Portal Dokazi u medicini ${ }^{13}$ Hrvatski Cochrane pokrenuo je krajem 2014. godine s ciljem davanja informacija građanima o različitim alternativnim i komplementarnim terapijama koje se nude na tržištu. Na portalu građani mogu poslati pitanje o različitim zdravstvenim tvrdnjama s kojima se promoviraju terapije i dijagnostički postupci alternativne medicine, a znanstvenici koji volontiraju na portalu analiziraju literaturu i objavljuju odgovore na pitanja o djelotvornosti i sigurnosti tih postupaka. Na taj način se građanima laicima pomaže u procjeni zdravstvenih tvrdnji koje se mogu naći u reklamama o terapijama koje se ne mogu dobiti na recept i koje uglavnom nisu registrirane kao lijekovi i medicinski proizvodi.

Također je organiziran niz edukacija za novinare, studente novinarstva i studente komunikologije o medicini temeljenoj na dokazima. Te su edukacije organizirane jer se u medijima svakodnevno mogu čuti i pročitati neutemeljene ili potpuno netočne tvrdnje o zdravlju. U okviru ovog projekta novinarima i studentima novinarstva i komunikologije predstavljeni su česti primjeri neutemeljenih i netočnih informacija, detaljno objašnjeno kako znamo da u medicini nešto djeluje ili ne djeluje, gdje mogu naći vjerodostojne informacije o zdravlju i kako prepoznati neutemeljene i netočne informacije o zdravlju kako ih ne bi prenosili dalje u svojim medijima.

Hrvatski Cochrane provodi brojne projekte popularizacije znanosti usmjerene na laike.

\section{OBJAVLJIVANJE COCHRANE SUSTAVNIH} PREGLEDA

U svibnju 2017. u Cochraneu su bila registrirana 73 autora s adresom iz Hrvatske. Od toga su 57 autori objavljenih Cochrane publikacija, uključujući sustavne preglede i protokole. Cilj Hrvatskog Cochranea je potaknuti više autora iz Hrvatske na uključenje u izradu Cochrane sustavnih pregleda koji su vrijedna publikacija. Cochrane Database of Systematic Reviews u kojoj se objavljuju Cochrane sustavni pregledi ima čimbenik odjeka (engl. impact factor) za 2015. godinu od 6.103. Doktorati koji se temelje na Cochrane sustavnim pregledima do sada su obranjeni na Medicinskim fakultetima u Rijeci i u Splitu. Doktorat koji se temelji na sustavnim pregledima novi je model doktorata s nizom prednosti za kandidata i mentora $^{14}$

\section{UKLJUČIVANJE U COCHRANE AKTIVNOSTI}

\section{U HRVATSKOJ}

Mrežna stranica Hrvatskog Cochranea ${ }^{15}$ redovito se održava te se na njoj može naći pregršt informacija o prošlim i aktualnim Cochrane aktivnostima u Hrvatskoj. Svi zainteresirani za uključivanje u Cochrane aktivnosti mogu se informirati na mrežnoj stranici Hrvatskog Cochranea, doći na Hrvatski Cochrane simpozij u Split, uključiti se kao prevoditelji Cochrane laičkih sažetaka ili glasovnih zapisa i sudjelovati u svim drugim aktivnostima Hrvatskog Cochranea prema svojim željama i sklonostima. 


\section{ZAKLJUČAK}

U prvih deset godina od svog osnutka Hrvatski Cochrane $u$ regiji je postigao zapažene rezultate $u$ promoviranju medicine temeljene na dokazima te se nadamo da će se isti tempo zadržati i u budućnosti, što nije jednostavno, s obzirom na to da su svi koji su angažirani oko Hrvatskog Cochranea i Cochrane aktivnosti u Hrvatskoj - volonteri.

Izjava o sukobu interesa: autori izjavljuju da ne postoji sukob interesa.

\section{LITERATURA}

1. Chalmers I. The Cochrane collaboration: preparing, maintaining, and disseminating systematic reviews of the effects of health care. Ann N Y Acad Sci 1993;703:156-65.

2. Smith R. The Cochrane collaboration at 20. BMJ 2013; 347:f7383.

3. Jadad AR, Moher M, Browman GP, Booker L, Siqouin C, Fuentes Met al. Systematic reviews and meta-analyses on treatment of asthma: critical evaluation. BMJ 2000; 320:537-40.

4. Olsen O, Middleton P, Ezzo J, Gotzsche PC, Hadhazy V, Herxheimer A et al. Quality of Cochrane reviews: assessment of sample from 1998. BMJ 2001;323:829-32.

5. Delaney A, Bagshaw SM, Ferland A, Laupland K, Manns B, Doig $C$. The quality of reports of critical care meta-analyses in the Cochrane Database of Systematic Reviews: an independent appraisal. Crit Care Med 2007;35:589-94.

6. Page MJ, Shamseer L, Altman DG, Tetzlaff J, Sampson $\mathrm{M}$, Tricco AC et al. Epidemiology and Reporting Charac- teristics of Systematic Reviews of Biomedical Research: A Cross-Sectional Study. PLoS Med 2016;13:e1002028.

7. Chandler J, Churchill R, Higgins J, Lasserson T, Tovey D. Methodological standards for the conduct of new Cochrane Intervention Reviews. Cochrane [Internet]. London, UK [cited 2017 May 31] Available from: http:// wounds.cochrane.org/sites/wounds.cochrane.org/files/public/uploads/MECIR_conduct_standards\%20 2.3\%2002122013_0.pdf. 2013.

8. Cochrane dokazi [Internet]. Split, Croatia [cited 2017 May 31]. Available from: http://www.cochrane.org/hr/ evidence.

9. Puljak L. Using social media for knowledge translation, promotion of evidence-based medicine and high-quality information on health. J Evid Based Med 2016;9: 4-7.

10. Gdje su dokazi? Bolja istraživanja za bolje zdravlje [Internet]. Split, Croatia [cited 2017 May 31]. Available from: http://hr.testingtreatments.org/procitajte-knjigugdje-su-dokazi/.

11. Nemam što izgubiti ako pokušam [Internet]. Split, Croatia [cited 2017 May 31]. Available from: http://croatia. cochrane.org/hr/knjizica-nemam-sto-izgubiti-ako-pokusam.

12. Glas razuma o ranom otkrivanju bolesti [Internet]. Split, Croatia [cited 2017 May 31]. Available from: http://croatia.cochrane.org/hr/izvori-informacija/knji\%C5\%BEicaglas-razuma-o-ranom-otkrivanju-bolesti.

13. Dokazi u medicini [Internet]. Split, Croatia [cited 2017 May 31]. Available from: www.dokaziumedicini.hr.

14. Puljak L, Sambunjak D. Cochrane systematic review as a PhD thesis: an alternative with numerous advantages. Biochemia Medica 2010;20:319-26.

15. Hrvatski Cochrane [Internet]. Split, Croatia [cited 2017 May 31]. Available from: www.cochrane.hr. 